\title{
Corrosion of steel in weakly acidic media at low $\mathrm{H}_{2} \mathrm{~S}$ concentrations
}

\author{
L.E. Tsygankova, ${ }^{1}$ A.A. Kostyakova, ${ }^{1}$ N. Alshikha ${ }^{1}$ and V.I. Vigdorovich ${ }^{2,3}$ \\ ${ }^{1}$ Derzhavin State University, ul. Internatsyonalnaya, 33, Tambov, \\ 392000 Russian Federation \\ ${ }^{2}$ Tambov State Technical University, ul. Sovetskaya, 106, Tambov, \\ 392000, Russian Federation \\ ${ }^{3}$ All-Russian Scientific Research Institute of Use of Machinery and Oil Products, \\ Novo-Rubezhnyi per., 28, Tambov, 392022 Russian Federation \\ E-mail:vits21@mail.ru
}

\begin{abstract}
The influence of low concentrations of $\mathrm{H}_{2} \mathrm{~S}(25-200 \mathrm{mg} / \mathrm{L})$ on the corrosion rate of St3 steel in model stratum water was studied by gravimetric, electrochemical methods and the linear polarization resistance method from ten-day experiments. In a simulated solution with $\mathrm{pH}=6$, an increase in the concentration of $\mathrm{H}_{2} \mathrm{~S}$ in the range $25-100 \mathrm{mg} / \mathrm{L}$ causes an increase in the protective effect of $\mathrm{H}_{2} \mathrm{~S}$. At $200 \mathrm{mg} / \mathrm{L} \mathrm{H}_{2} \mathrm{~S}$, the corrosion rate rises, but remains lower than in the solution without $\mathrm{H}_{2} \mathrm{~S}$. Introduction of an organic inhibitor to solutions containing $\mathrm{H}_{2} \mathrm{~S}$ in these concentrations enhances the protective effect. Electron microscopy was used to characterize the state of the metal surface after corrosion. In a simulated solution with a lower $\mathrm{pH}$ (3.6), only $25 \mathrm{mg} / \mathrm{L}$ of $\mathrm{H}_{2} \mathrm{~S}$ causes a decrease in the corrosion rate of the steel.
\end{abstract}

Key words: steel, hydrogen sulphide, protective effect, model stratum water, inhibitor, impedance, polarization.

Received: December 19, 2017. Published: February 12, 2018

doi: $\underline{10.17675 / 2305-6894-2018-7-1-9}$

\section{Introduction}

Earlier it was repeatedly shown that the corrosion rate of steel decreases in time in both inhibited and uninhibited hydrogen sulfide solutions [1-3]. This is interpreted as the result of the formation of the protective film of corrosion products on the surface, and in the presence of an inhibitor of organic nature, a lower corrosion rate is achieved in the same time period than in its absence. The observed pattern is obviously due to the combined effect of the inhibitor and the shielding layer of the corrosion products. This synergistic effect of the inhibiting additive and $\mathrm{H}_{2} \mathrm{~S}$ was explained by the fact that organic additives react chemically with hydrogen sulphide, forming insoluble compounds representing the phase barrier on the metal surface. In $[4,5]$, a method was proposed for estimating the contribution of the inhibitor and shielding film of corrosion products of steel to the overall protective effect in 
hydrogen sulfide media. For this purpose, measurements of the instantaneous corrosion rate of steel were made during $24 \mathrm{~h}$ using a corrosion meter operating on the basis of the polarization resistance method. These data showed that the rate of corrosion in a medium with $\mathrm{H}_{2} \mathrm{~S}$ decreases with time, especially in solutions containing an inhibitor, and reaches the steady-state value or close to it by the end of $24 \mathrm{~h}$. Based on these results, the contribution of the inhibitor and film of corrosion products formed during $24 \mathrm{~h}$ was calculated.

But the studies of corrosion behavior of steel for 10 and 30 days have shown that the corrosion rate of steel continues to decrease in time and with such long-term experiments, which made it possible to calculate the contributions of the inhibitor and the film of corrosion products on these time intervals. It has been shown that an increase in the duration of corrosion tests in the NACE $+\mathrm{H}_{2} \mathrm{~S}$ media leads to an increase in the contribution of the film of corrosion products to the overall protective effect and to a decrease in the contribution of the inhibitor [6].

The aim of this work is to study the influence of small concentrations of hydrogen sulphide on the corrosion rate of St3 steel in weakly acidic media in the absence and presence of an inhibitor.

\section{Experimental}

Corrosion tests, electrochemical and impedance measurements were performed on samples of steel St3 with composition, mass.\%: $\mathrm{C}-0.2 ; \mathrm{Mn}-0.5 ; \mathrm{Si}-0.15 ; \mathrm{P}-0.04 ; \mathrm{S}-0.05$; $\mathrm{Cr}-0.30 ; \mathrm{Ni}-0.20 ; \mathrm{Cu}-0.20 ; \mathrm{Fe}-98.36$.

A condensation product of fatty acids and polyethylenepolyamines in an alcoholhydrocarbon solvent (manufactured by ZAO "AMDOR", St. Petersburg) was used as the inhibitor.

The following media were studied as the working solutions: NACE medium recommended by the National Association of Corrosion Engineers (USA); composition, g/L: $\mathrm{NaCl}-5 ; \mathrm{CH}_{3} \mathrm{COOH}-0.25$, and model stratum water $\mathrm{M} 1$ (simulation of stratum water of the Samotlor oil field) with the content, $\mathrm{g} / \mathrm{L}: \mathrm{NaCl}-17 ; \mathrm{CaCl}_{2}-0.2 ; \mathrm{MgCl}_{2} \cdot 6 \mathrm{H}_{2} \mathrm{O}-0.2$; $\mathrm{NaHCO}_{3}-0.8$. Various amounts $\mathrm{H}_{2} \mathrm{~S}(25-200 \mathrm{mg} / \mathrm{L})$ were added to the investigated media. Distilled water was used; hydrochloric acid and salts were of "chemically pure" qualifications. Hydrogen sulphide was produced directly in the working solution, for which calculated amounts of $\mathrm{Na}_{2} \mathrm{~S}$ and $\mathrm{HCl}$ were introduced, corresponding to the equation:

$$
\mathrm{Na}_{2} \mathrm{~S}+2 \mathrm{HCl}=\mathrm{H}_{2} \mathrm{~S}+2 \mathrm{NaCl}
$$

The concentration of hydrogen sulphide was controlled iodometrically.

The method of gravimetric corrosion testing was generally accepted [2]. The duration of the experiments was 10 days. The protective effect of additives $(Z)$ was calculated by the formula:

$$
\left.Z, \%=100\left[\left(K_{0}-K_{\mathrm{i}}\right) / K_{0}\right)\right],
$$


where $K_{0}$ and $K_{\mathrm{i}}$ are the corrosion rates in the absence and in the presence of additives in the test solutions, respectively.

Polarization measurements were carried out using an IPC-Pro potentiostat (produced by A.N. Frumkin Institute of Physical Chemistry and Electrochemistry, RAS) by the potentiodynamic method with a potential scan rate of $0.66 \mathrm{mV} / \mathrm{s}$.

Impedance spectra were studied in the frequency range $(\omega / 2 \pi)$ of $10 \mathrm{kHz}-0.05 \mathrm{~Hz}$ with an alternating voltage amplitude of $10 \mathrm{mV}$, using an electrochemical measuring complex from Solartron (UK) consisting of a 1255 SI impedance analyzer and a SI 1287 potentiostat [7].

Investigations of the instantaneous corrosion rate of St3 steel were carried out using an Expert-004 corrosion meter operating on the basis of the linear polarization resistance method using a two-electrode scheme [8].

Electron microscopy (JSM-6390) was used to characterize the surface of the samples after the tests.

\section{Results and discussion}

\section{M1 Medium $(p H \approx 6)$}

In the first days of the presence of electrodes in an M1 solution containing $25 \mathrm{mg} / \mathrm{L}$ of hydrogen sulfide, a black loose coating is formed on the surface, which falls as a sludge to the bottom of the vessels. After 10 days, its residues are easily removed from the surface of the samples, which are covered with a dense, dark polished type sulfide film. No lesions on the surface are observed and it looks smoother than before exposure in the indicated solution (Figure 1). The results of calculating the corrosion rate showed that its value decreases with introduction of hydrogen sulfide to $\mathrm{M} 1$ and with an increase in its concentration to $100 \mathrm{mg} / \mathrm{L}$ (Table 1). A further increase in the $\mathrm{H}_{2} \mathrm{~S}$ concentration to $200 \mathrm{mg} / \mathrm{L}$ leads to an increase in the corrosion rate of the steel, but it remains lower than in the solution without hydrogen sulphide. This makes it possible to calculate the protective effect of hydrogen sulphide, the presence of which promotes the formation of a protective film of corrosion products.

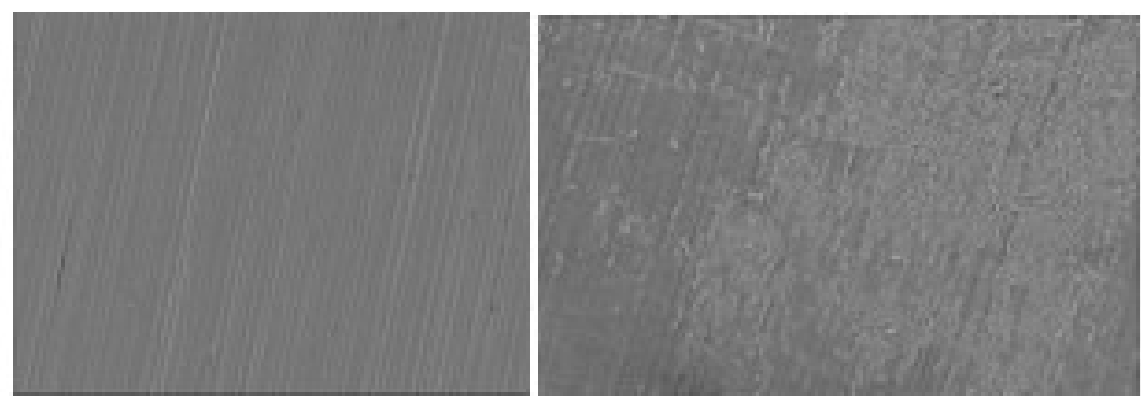

Figure 1. SEM micrographs of a mechanically polished steel surface (left) and a steel surface after 10 days exposure to M1 solution containing $25 \mathrm{mg} / \mathrm{L} \mathrm{H}_{2} \mathrm{~S}$ (right). Magnification x300. 
Table 1. Influence of $\mathrm{H}_{2} \mathrm{~S}$ concentration in $\mathrm{M} 1$ medium on corrosion rate of steel St3, according to data of 10-day tests.

\begin{tabular}{cccccc}
\hline $\boldsymbol{C}_{\mathrm{H}_{2} \mathrm{~s}}, \mathbf{m g} / \mathbf{L}$ & $\mathbf{0}$ & $\mathbf{2 5}$ & $\mathbf{5 0}$ & $\mathbf{1 0 0}$ & $\mathbf{2 0 0}$ \\
\hline$K, \mathrm{~g} /\left(\mathrm{m}^{2} \cdot \mathrm{h}\right)$ & 0.0429 & 0.0347 & 0.0309 & 0.0255 & 0.0386 \\
$Z_{\mathrm{H}_{2} \mathrm{~S}}, \%$ & - & 19 & 28 & 40 & 10 \\
\hline
\end{tabular}

From Table 1 it follows that an increase in the concentration of hydrogen sulphide contributes to the growth of the protective effect to a concentration of $100 \mathrm{mg} / \mathrm{L}$, while a further increase to $200 \mathrm{mg} / \mathrm{L}$ reduces it. It can be assumed that minor corrosion losses of the samples occurred in the initial period of time and are associated with the dissolution of the active areas of the surface, after which the polishing effect of the sulphide film was manifested.

In a solution of M1 containing $25 \mathrm{mg} / \mathrm{L}$ of $\mathrm{H}_{2} \mathrm{~S}$, addition of the inhibitor promotes an increase in the protective effect only at $C_{\text {Inh }}=100-200 \mathrm{mg} / \mathrm{L}$ (Table 2), which is due to the total effect of the sulfide film and the inhibitor $\left(Z_{\Sigma}\right)$. At a concentration of $25 \mathrm{mg} / \mathrm{L}$, the rate of corrosion remains the same as in its absence.

Table 2. Effect of inhibitor concentration on corrosion rate and protective effect $\left(Z_{\Sigma}\right)$ in M1 medium containing $25 \mathrm{mg} / \mathrm{L} \mathrm{H}_{2} \mathrm{~S}$ with respect to corrosion rate $\left(\mathrm{K}_{0}\right)$ of steel in the absence of hydrogen sulphide $\left(\mathrm{K}_{0}=0.0429 \mathrm{~g} /\left(\mathrm{m}^{2} \mathrm{~h}\right)\right)$

\begin{tabular}{ccccc}
\hline $\boldsymbol{C}_{\mathbf{I n h}}, \mathbf{m g} / \mathbf{l}$ & $\mathbf{0}$ & $\mathbf{2 5}$ & $\mathbf{1 0 0}$ & $\mathbf{2 0 0}$ \\
\hline$K, \mathrm{~g} /\left(\mathrm{m}^{2} \cdot \mathrm{h}\right)$ & 0.0347 & 0.0347 & 0.0308 & 0.0313 \\
$Z_{\Sigma}, \%$ & 19 & 19 & 28 & 27 \\
\hline
\end{tabular}

Addition of increasing hydrogen sulfide concentrations to $\mathrm{M} 1$ containing $25 \mathrm{mg} / \mathrm{L}$ inhibitor promotes an increase in the overall protective effect (Table 3). And only at $C_{\mathrm{H}_{2} \mathrm{~S}}=$ $200 \mathrm{mg} / \mathrm{L}$, its value decreases to that observed at the minimum concentration of hydrogen sulphide.

Table 3. Joint protective effect of $25 \mathrm{mg} / \mathrm{L}$ inhibitor and different concentration of $\mathrm{H}_{2} \mathrm{~S}$ in $\mathrm{M} 1$ medium with respect to corrosion rate $\left(K_{0}\right)$ of steel in the absence of hydrogen sulphide and an inhibitor $\left(K_{0}=\right.$ $0.0429 \mathrm{~g} /\left(\mathrm{m}^{2} \cdot \mathrm{h}\right)$.

\begin{tabular}{ccccc}
\hline $\boldsymbol{C}_{\mathbf{H}_{2} \mathbf{s}}, \mathbf{m g} / \mathbf{L}$ & $\mathbf{2 5}$ & $\mathbf{5 0}$ & $\mathbf{1 0 0}$ & $\mathbf{2 0 0}$ \\
\hline$K, \mathrm{~g} /\left(\mathrm{m}^{2} \cdot \mathrm{h}\right)$ & 0.0347 & 0.0182 & 0.0221 & 0.0349 \\
$Z_{\Sigma}, \%$ & 19 & 58 & 48 & 19 \\
\hline
\end{tabular}


The data given in Tables 1 and 3 show that, obviously, with an increase in the concentration of hydrogen sulfide to $200 \mathrm{mg} / \mathrm{L}$, the structure of the sulfide film on the metal surface changes, leading to a decrease in its protective properties.

Impedance measurements carried out in a solution of M1 containing $25 \mathrm{mg} / \mathrm{L} \mathrm{H}_{2} \mathrm{~S}$ for several hours showed an increase in the diameters of the semicircles in the Nyquist diagram in time, which indicates an increase in the total resistance in the system, and, therefore, a decrease in the corrosion rate due to formation of the protective sulphide film on the surface (Figure 2).

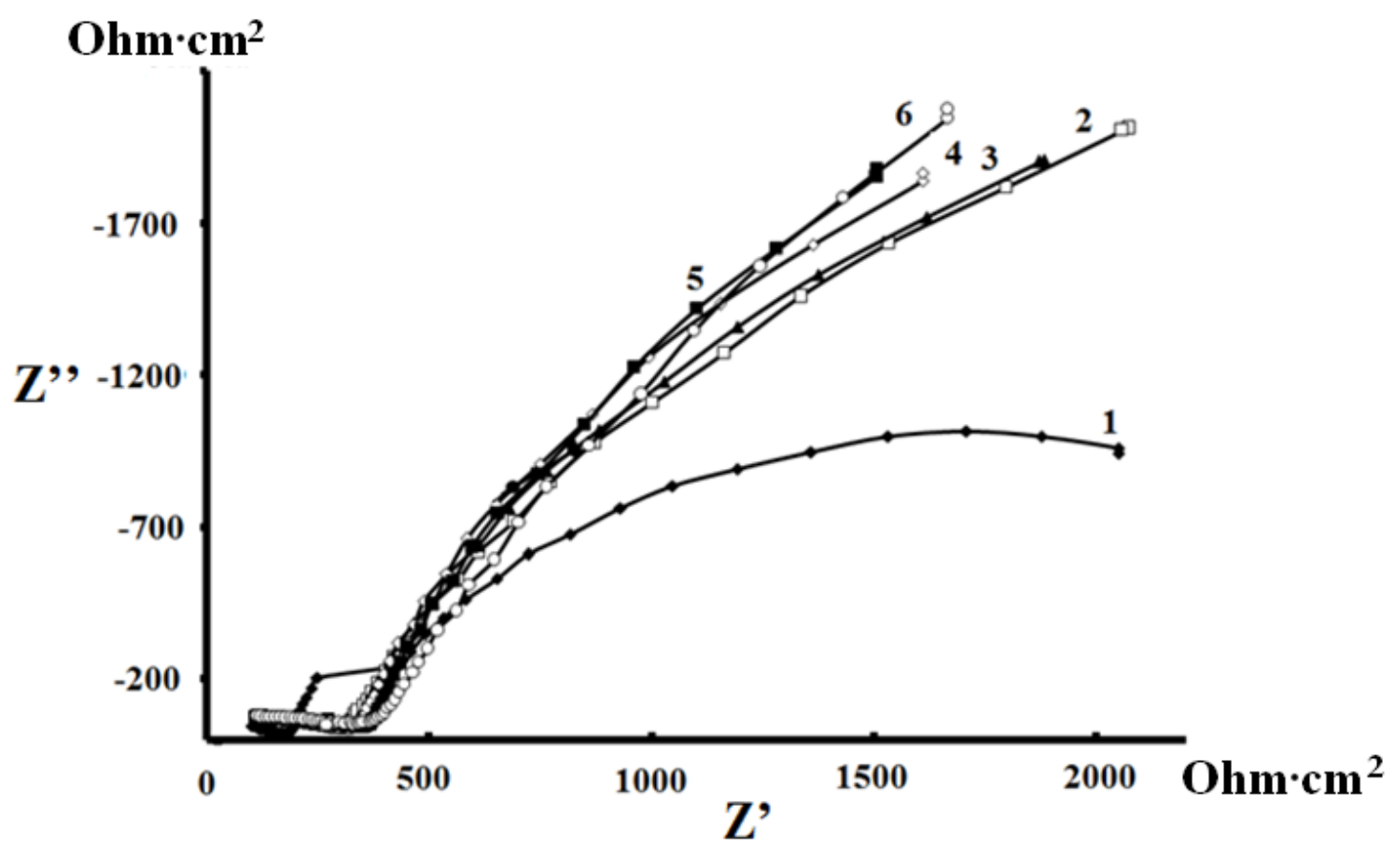

Figure 2. Nyquist diagrams on steel at $\mathrm{E}_{\text {cor }}$ in $\mathrm{M} 1$ medium containing $25 \mathrm{mg} / \mathrm{L}$ of hydrogen sulfide at different exposure times, $\tau$, h: $1-0.25 ; 2-0.5 ; 3-1.0: 4-2.0 ; 5-4.0 ; 6-6.0$.

The results of measuring the instantaneous corrosion rate of steel by the polarization resistance method for 10 days in M1 medium containing $25 \mathrm{mg} / \mathrm{L}$ of hydrogen sulfide and various inhibitor additives are shown in Figure 3.

It is seen that on the first days there is an increase in the rate of corrosion, especially in the absence of an inhibitor and at its minimum concentration, caused by the dissolution of work-hardened metal on the surface of the samples and accompanied by the formation of a slurry, followed by a decline due to the formation of a protective sulphide film of products firmly adhered to the surface. As previously noted, the corrosion rate has the same values when $25 \mathrm{mg} / \mathrm{L} \mathrm{H}_{2} \mathrm{~S}$ is present in the solution in the absence and in the presence of $25 \mathrm{mg} / \mathrm{L}$ inhibitor (Table 2). Accordingly, the instantaneous corrosion rate in 
these solutions is characterized by an almost identical time dependence (Figure 3). In solutions with a higher inhibitor concentration, the initial increase in corrosion rate over time is significantly lower. And at $200 \mathrm{mg} / \mathrm{L}$ of the inhibitor, it is completely absent. Apparently, a higher concentration of the inhibitor promotes a more rapid formation of the protective film.

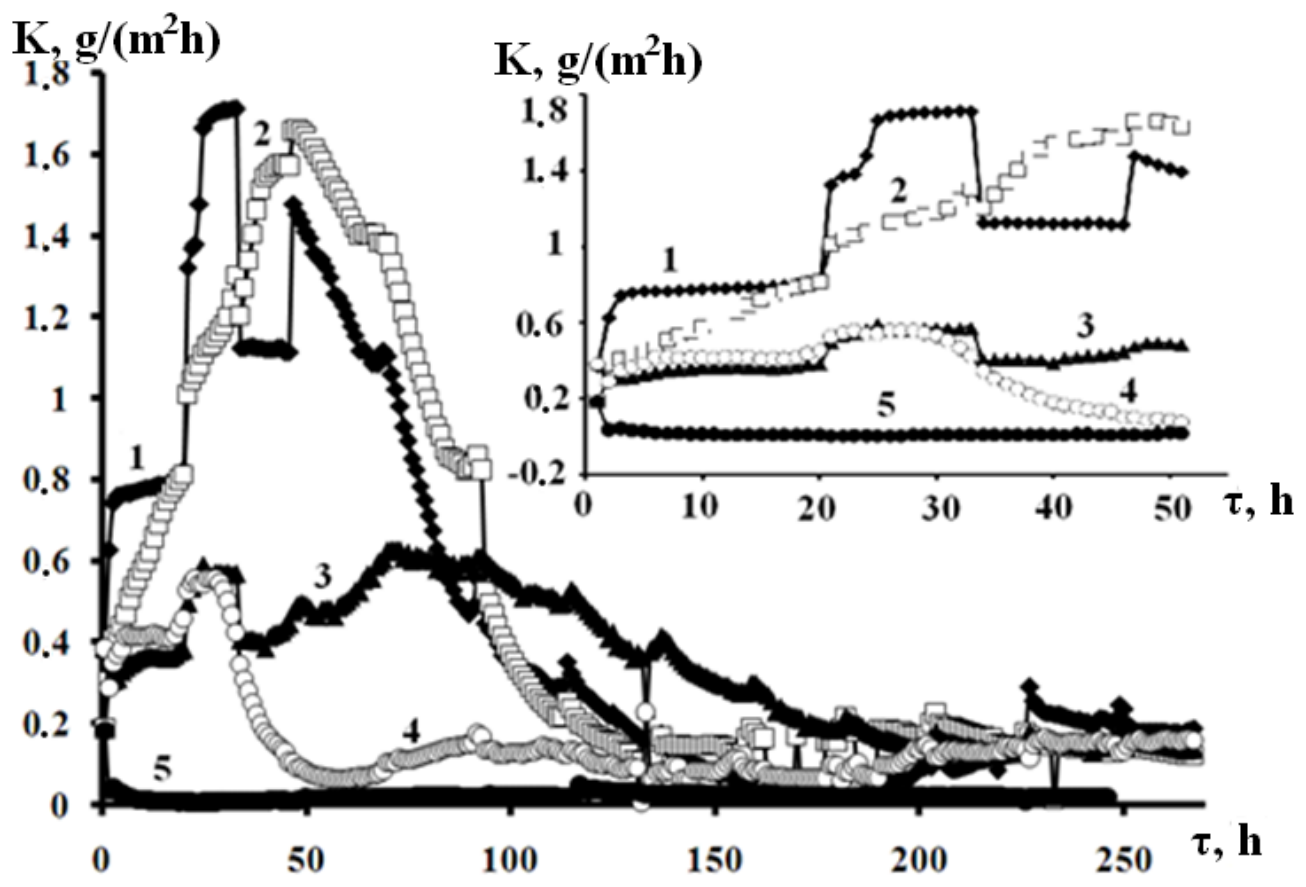

Figure 3. Dependence of the instantaneous corrosion rate of $\mathrm{St} 3$ steel versus time in $\mathrm{M} 1$ medium containing $25 \mathrm{mg} / \mathrm{L} \mathrm{H}_{2} \mathrm{~S}$ and different inhibitor concentrations, $\mathrm{mg} / \mathrm{L}: 1-0 ; 2-25$; $3-50 ; 4-100 ; 5-200$.

Potentiodynamic polarization curves measured on steel in M1 solutions with different concentrations of hydrogen sulfide in the absence and presence of an inhibitor are shown in Figure 4. It follows from them that an increase in the concentration of hydrogen sulphide in both cases practically does not affect the course of the cathodic polarization curves, but leads to inhibition of the anodic ionization process with a reaction order on $\mathrm{H}_{2} \mathrm{~S}$ concentration equal to $-1.4 \pm 0.1$. Thus, even at the initial moment of time after immersion of the electrode in the solution, which corresponds to the conditions for measuring the polarization curves, the decrease in the corrosion rate of steel is due to the retardation of the anodic process. And hydrogen sulphide at concentrations up to $200 \mathrm{mg} / \mathrm{L}$ acts as an inhibitor. Moreover, its effect practically does not depend on the presence or absence of a corrosion inhibitor. Determination of the order of the anodic reaction on the inhibitor at different concentrations of hydrogen sulphide in solution showed that at a minimum $\mathrm{H}_{2} \mathrm{~S}$ concentration the order is -1 and decreases with increasing hydrogen sulfide content in the solution. There is no effect of the inhibitor on the cathodic process. 

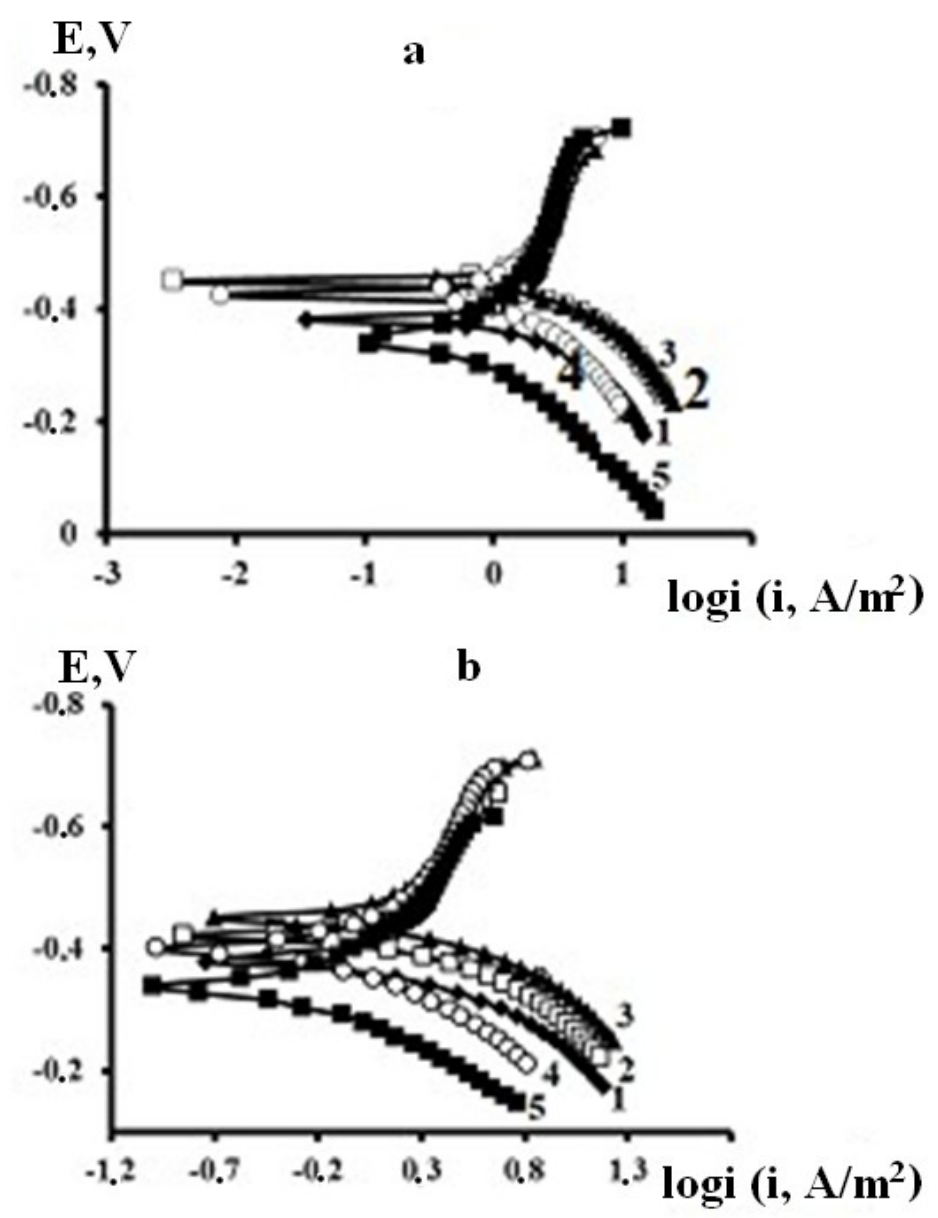

Figure 4. Potentiodynamic polarization curves measured on steel in M1 medium with different concentrations of hydrogen sulphide in the absence (a) and in the presence of $100 \mathrm{mg} / \mathrm{L}$ inhibitor (b). $C_{\mathrm{H}_{2} \mathrm{~S}}, \mathrm{mg} / \mathrm{L}: 1-0 ; 2-25 ; 3-50 ; 4-100 ; 5-200$.

The protective effect of small concentrations of hydrogen sulphide (from 5 to 500 $\mathrm{mg} / \mathrm{L}$ ) with respect to iron was observed by the authors of [9] in a $3 \% \mathrm{NaCl}$ solution saturated with $\mathrm{CO}_{2}$. The combination of impedance and surface spectroscopic studies allowed them to conclude that at an $\mathrm{H}_{2} \mathrm{~S}$ concentration of $5 \mathrm{mg} / \mathrm{L}$, its inhibitory effect is due to sulfur adsorption on the air-formed iron oxide present on the metal surface. At a higher concentration of hydrogen sulphide, a porous layer of sulphide or oxysulfide forms due to the conversion of iron oxide into them. Its protective properties are lower than for the adsorption layer formed at the minimum concentration of $\mathrm{H}_{2} \mathrm{~S}$. The data obtained by us agree with the explanations of the inhibitory effect of hydrogen sulphide proposed in [9], although in the M1 medium under investigation there is no carbon dioxide. Obviously, the atmosphere of carbon dioxide promoted the absence of oxygen in the reaction medium. In our case, it was available. But this did not prevent the manifestation of the protective effect of hydrogen sulphide in a concentration of up to $200 \mathrm{mg} / \mathrm{L}$. 
NACE medium $(p H=3.6)$

In NACE medium, the corrosion rate was higher than in M1, which is most likely due to a lower $\mathrm{pH}$. In 10-day tests in the presence of $25 \mathrm{mg} / \mathrm{L} \mathrm{H}_{2} \mathrm{~S}$, the corrosion rate decreases, like under similar conditions in M1, with a close $Z$ value (21\%) (Table 4). However, a further increase in the concentration of hydrogen sulphide up to $200 \mathrm{mg} / \mathrm{L}$ leads to a $1.07-1.5$ fold increase in the corrosion rate.

Table 4. Influence of $\mathrm{H}_{2} \mathrm{~S}$ concentration in NACE medium on corrosion rate of steel St3 according to 10day tests.

\begin{tabular}{cccccc}
\hline $\boldsymbol{C}_{\mathrm{H}_{2} \mathrm{~S}}, \mathbf{m g} / \mathbf{L}$ & $\mathbf{0}$ & $\mathbf{2 5}$ & $\mathbf{5 0}$ & $\mathbf{1 0 0}$ & $\mathbf{2 0 0}$ \\
\hline$K, \mathrm{~g} /\left(\mathrm{m}^{2} \cdot \mathrm{h}\right)$ & 0.0728 & 0.0571 & 0.1124 & 0.0785 & 0.1077 \\
$Z_{\mathrm{H}_{2} \mathrm{~S}}, \%$ & - & 21 & - & - & - \\
\hline
\end{tabular}

The combined protective effect of $25 \mathrm{mg} / \mathrm{L} \mathrm{H}_{2} \mathrm{~S}$ and an inhibitor at concentrations up to $200 \mathrm{mg} / \mathrm{L}$ has a higher protective effect than in M1 (Table 5).

Table 5. Effect of inhibitor concentration on corrosion rate and protective effect $\left(Z_{\Sigma}\right)$ in NACE medium containing $25 \mathrm{mg} / \mathrm{L}$ of $\mathrm{H}_{2} \mathrm{~S}$ with respect to corrosion rate $\left(K_{0}\right)$ of steel in the absence of hydrogen sulphide $\left(K_{0}=0.0728 \mathrm{~g} /\left(\mathrm{m}^{2} \cdot \mathrm{h}\right)\right)$.

\begin{tabular}{cccccc}
\hline $\boldsymbol{C}_{\text {Inh }}, \mathbf{m g} / \mathbf{L}$ & $\mathbf{0}$ & $\mathbf{2 5}$ & $\mathbf{5 0}$ & $\mathbf{1 0 0}$ & $\mathbf{2 0 0}$ \\
\hline$K, \mathrm{~g} /\left(\mathrm{m}^{2} \cdot \mathrm{h}\right)$ & 0.0571 & 0.0550 & 0.0584 & 0.0504 & 0.0416 \\
$Z_{\Sigma}, \%$ & 21 & 24 & 20 & 31 & 43 \\
\hline
\end{tabular}

And an increase in the concentration of $\mathrm{H}_{2} \mathrm{~S}$ to $200 \mathrm{mg} / \mathrm{L}$ in solution with a $25 \mathrm{mg} / \mathrm{L}$ inhibitor does not lead to an increase in the protective effect (Table 6).

Table 6. Combined protective effect of $25 \mathrm{mg} / \mathrm{L}$ inhibitor and different concentration of $\mathrm{H}_{2} \mathrm{~S}$ in NACE medium with respect to corrosion rate $\left(K_{0}\right)$ of steel in the absence of hydrogen sulphide and an inhibitor $\left(K_{0}=0.0728 \mathrm{~g} /\left(\mathrm{m}^{2} \cdot \mathrm{h}\right)\right)$.

\begin{tabular}{ccccc}
\hline $\boldsymbol{C}_{\mathbf{H}_{2} \mathbf{S}}, \mathbf{m g} / \mathbf{L}$ & $\mathbf{2 5}$ & $\mathbf{5 0}$ & $\mathbf{1 0 0}$ & $\mathbf{2 0 0}$ \\
\hline$K, \mathrm{~g} /\left(\mathrm{m}^{2} \cdot \mathrm{h}\right)$ & 0.0550 & 0.0799 & 0.0871 & 0.0648 \\
$Z_{\Sigma}, \%$ & 24 & - & - & 11 \\
\hline
\end{tabular}

Determination of the order of the anodic reaction on the inhibitor at different concentrations of hydrogen sulphide in solution, according to the polarization curves, showed that at a minimum concentration of $\mathrm{H}_{2} \mathrm{~S}$, the order is -1.3 , whereas in the presence 
of $200 \mathrm{mg} / \mathrm{L}$ hydrogen sulfide, its value becomes -1.1 . The effect of the inhibitor on the cathodic process, like in the M1 medium with hydrogen sulphide, is practically absent.

We note that according to a ten-point scale of corrosion resistance [10], ferrous

metals, including carbon steel with a corrosion rate in the range of $0.045-0.090 \mathrm{~g} /\left(\mathrm{m}^{2} \cdot \mathrm{h}\right)$, are considered stable and have 5 points.

The presence of $25 \mathrm{mg} / \mathrm{L} \mathrm{H}_{2} \mathrm{~S}$ in the M1 solution reduces the corrosion resistance to 4 points. The same is true for M1 containing $25 \mathrm{mg} / \mathrm{L}$ of inhibitor and hydrogen sulfide in the amount of 25-200 mg/L (Tables 1 and 3). In NACE solution, these compositions do not reduce the corrosion resistance points (Table 6), which is probably associated with higher acidity, but at the same time, an increase in $C_{\text {Inh }}$ in the presence of $25 \mathrm{mg} / \mathrm{L} \mathrm{H}_{2} \mathrm{~S}$ systematically increases the $Z$ value (Table 5).

\section{Conclusion}

According to ten-day experiments at room temperature, hydrogen sulfide in a concentration of $25-200 \mathrm{mg} / \mathrm{L}$ exhibits an inhibitory effect with respect to St3 steel in M1 model stratum water with $\mathrm{pH}=6$. The inhibitory effect of hydrogen sulphide is associated with the formation of a surface film of iron sulphide and is confirmed by potentiodynamic, impedance measurements and the linear polarization resistance method. Addition of an organic inhibitor into hydrogen sulphide solutions enhances the protective effect.

In NACE simulated stratum water with $\mathrm{pH}=3.6$, hydrogen sulphide shows an inhibitory effect only at a concentration of $25 \mathrm{mg} / \mathrm{L}$. Addition of an organic inhibitor also enhances the protective effect, like in M1.

The experimental results were obtained using the equipment of the Center for Collective Use of Scientific Equipment of TSU named after GR. Derzhavin.

\section{References}

1. Ya.R. Kim, L.E. Tsygankova and V.I. Kichigin. Korroz.: Mater. Zashch., 2005, no. 8, 30 (in Russian).

2. L.E. Tsygankova, A.V. Mozharov, S.S. Ivanischenkov and E.S. Kos'yanenko, Praktika Protivokorroz. Zashch., 2006, 40, no. 2, 49 (in Russian).

3. V.I. Vigdorovich, L.E. Tsygankova and A.I. Fedotova, Praktika Protivokorroz. Zashch., 2010, 55, no. 1, 55 (in Russian).

4. V.I. Vigdorovich and S.A. Zakurnaev. Prot. Met. Phys. Chem. Surf., 2009, 45, 812.

5. V.I. Vigdorovich, L.E. Tsygankova and N.V. Shel, Surf. Interface Anal., 2010, 42, 626.

6. P.V. Lebedev, Ph.D. (Chem. Sci.) Dissertation, Author's abstract, 2015, Tambov (in Russian).

7. L.E. Tsygankova, M.N. Esina, V.I. Vigdorovich and N.V. Shel, Int. J. Corros. Scale Inhib., 2014, 3, no. 1, 48. doi: 10.17675/2305-6894-2014-3-1-048-058 
8. N.G. Anufriev and M. Atef El-Sayed. Korroz.: Mater. Zashch., 2010, no. 1, 44 (in Russian).

9. E. Abelev, T.A. Ramanarayanan and S.L. Bernasek, J. Electrochem. Soc., 2009, 156, no. 9,331 .

10. V.V. Romanov, Metody issledovaniya korrozii metallov (Methods of metal corrosion study), Moscow, Metallurgiya, 1965 (in Russian). 